\title{
BMJ Open Newborn signal functions in Bangladesh: identification through expert consultation and assessment of readiness among public health facilities - study protocol using Delphi technique
}

\author{
Ahmed Ehsanur Rahman (D) , ${ }^{1}$ Goutom Banik, ${ }^{1}$ Shema Mhajabin (D) , \\ Tazeen Tahsina, ${ }^{1}$ Md. Jahurul Islam, ${ }^{2}$ Farid Uddin Ahmed, ${ }^{3}$ Mushair UI Islam, ${ }^{2}$ \\ Md Abdul Mannan, ${ }^{4}$ Sanjoy Kumer Dey, ${ }^{4}$ Shamina Sharmin, ${ }^{5}$ Fida Mehran, ${ }^{6}$ \\ Mahbuba Khan, ${ }^{7}$ Anisuddin Ahmed, ${ }^{1}$ Ahmed Al Sabir, ${ }^{8}$ Shahin Sultana, ${ }^{9}$ \\ Ziaul Ahsan, ${ }^{10}$ Sayed Rubayet, ${ }^{10}$ Joby George, ${ }^{11}$ Afsana Karim, ${ }^{11}$ \\ Mohammod Shahidullah, ${ }^{4}$ Shams El Arifeen, ${ }^{1}$ On behalf of NSF-BD study group
}

To cite: Rahman AE, Banik G, Mhajabin S, et al. Newborn signal functions in Bangladesh: identification through expert consultation and assessment of readiness among public health facilities—study protocol using Delphi technique. BMJ Open 2020;10:e037418. doi:10.1136/ bmjopen-2020-037418

- Prepublication history for this paper is available online. To view these files, please visit the journal online (http://dx.doi. org/10.1136/bmjopen-2020037418).

AER and $G B$ are joint first authors.

Received 09 February 2020 Revised 10 July 2020 Accepted 13 July 2020

Check for updates

(c) Author(s) (or their employer(s)) 2020. Re-use permitted under CC BY-NC. No commercial re-use. See rights and permissions. Published by BMJ.

For numbered affiliations see end of article.

Correspondence to Dr Ahmed Ehsanur Rahman; ehsanur@icddrb.org

\section{ABSTRACT}

Introduction There is a set of globally accepted and nationally adapted signal functions for categorising health facilities for maternal services. Newborn resuscitation is the only newborn intervention which is included in the WHO recommended list of emergency obstetric care signal functions. This is not enough to comprehensively assess the readiness of a health facility for providing newborn services. In order to address the major causes of newborn death, the Government of Bangladesh has prioritised a set of newborn interventions for national scale-up, the majority of which are facility-based. Effective delivery of these interventions depends on a core set of functions (skills and services). However, there is no standardised and approved set of newborn signal functions (NSFs) based on which the service availability and readiness of a health facility can be assessed for providing newborn services. Thus, this study will be the first of its kind to identify such NSFs. These NSFs can categorise health facilities and assist policymakers and health managers to appropriately plan and adequately monitor the progress and performance of health facilities delivering newborn healthcare.

Methods and analysis We will adopt the Delphi technique of consensus building for identification of NSFs and 1-2 indicator for each function while employing expert consultation from relevant experts in Bangladesh. Based on the identified NSFs and signal function indicators, the existing health facility assessment (HFA) tools will be updated, and an HFA survey will be conducted to assess service availability and readiness of public health facilities in relation to the new NSFs. Descriptive statistics (proportion) with a 95\% Cl will be used to report the level of service availability and readiness of public facilities regarding NSFs.

Ethics and dissemination Ethical approval was obtained from Research Review and Ethical Review Committee of

\section{Strengths and limitations of this study}

This is the first study to identify widely agreed on newborn signal functions (NSFs) for Bangladesh.

- This study will adopt the validated and widely used Delphi methodology to synthesise experts' opinions capitalising on their knowledge and experience in newborn health practice and newborn health research.

- The existing health facility assessment tool will be updated to test the NSFs in public health facilities.

- There will be experts who will decline or will not be available to participate in the study and who may have different opinions than the experts who participated.

icddr, b (PR-17089). Results will be disseminated through meetings, seminars, conference presentations and international peer-review journal articles.

\section{INTRODUCTION}

While during the Millenium Development Goals (MDG) era a $53 \%$ reduction of underfive mortality was observed, declining from 91 per 1000 live births in 1990 to 43 per 1000 live births in 2015, the decline in neonatal mortality was only of $47 \%$ which was much lower than under-five mortality. ${ }^{1}$ Moving forward from the MDG era, in September 2015, the United Nations (UN) General Assembly adopted the sustainable development goals (SDGs) for the next 15 years with 17 goals and 169 targets. $^{2}$ Learning from 
the MDG experience, where there was no specific target related to newborn health, the third SDG goal has set a specific target (3.1) for reducing neonatal mortality. ${ }^{2}$ The aim is to end all preventable neonatal death and to reduce the neonatal mortality rate of all countries to below 12 per 1000 live births by $2030 .^{2}$ Focusing on newborn health is, therefore, a global priority for accelerating progress towards child survival and reaching the SDG targets.

Bangladesh was one of the 25 countries to reach the MDG 4 target. $^{3}{ }^{4}$ Despite this remarkable progress, Bangladesh still suffers from one of the highest neonatal mortality rates in the world (30 per 1000 live births) which accounts for around $61 \%$ of all under-five deaths. ${ }^{5}$ Considering this high burden, the Government of Bangladesh (GoB) has prioritised newborn health and committed to achieving the SDG target by reducing newborn mortality to 12 per 1000 live births or below. Bangladesh every newborn action plan and the National Newborn Health Programme in fourth Health Sector Programme (20162022) of Bangladesh have prioritised a set of critical interventions for national scale-up to address the major causes of newborn death. ${ }^{6}$ The majority of these interventions require specialised and facility based care and hence need a strong health system to deliver the required services. ${ }^{78}$

Service availability and readiness of health facilities for delivering specific interventions can be measured through a set of signal functions. Signal functions are specific skills of the service providers or availability of specific services through which an intervention can be delivered in a health facility. Unfortunately, to date, there are no globally and nationally recognised signal functions through which the service availability and readiness of a health facility can be assessed for delivering newborn services. Additionally, there is no tool that can comprehensively assess the service availability and readiness of health facilities for newborn services.

In 1986, the WHO published a list of functions necessary for providing obstetric care in first level referral facilities. ${ }^{9}$ In 1997, a shorter list of functions was selected to form this list to treat the direct obstetric complications that cause the majority of maternal deaths around the globe. ${ }^{10}$ The shorter list of functions is known as the Emergency and Obstetric Care (EmOC) signal functions. Based on these EmOC signal functions, health facilities are classified as basic emergency obstetric care (BEmOC) or comprehensive obstetric care (CEmOC). A BEmOC facility should have seven signal functions and a CEmOC facility should have two additional signal functions (total nine). Newborn resuscitation is the only function related to a newborn intervention which is included in the WHO recommended EmOC signal functions. ${ }^{11}$ This is not enough to adequately assess the service availability and readiness of a health facility to cater to newborn services.

GoB has decided to scale up a set of newborn interventions nationally. ${ }^{12}$ The importance of a set of signal functions for appropriately categorising health facilities concerning newborn services hold paramount importance for policy and programme planning. Considering the need and importance, the National Newborn Health Programme and Integrated Managment of Childhood Illness (IMCI) (NNHP \& IMCI) of Directorate General of Health Services (DGHS) has adopted identification of newborn signal functions (NSFs) as a priority activity for appropriate planning and effective scale-up of newborn interventions in Bangladesh. This study has been designed to address the following research objectives:

Objective 1: to identify a set of NSFs for health facilities for adequately providing newborn services.

Objective 2: to select a set of indicators for assessing service availability and readiness of health facilities for providing services as per the NSFs.

Objective 3: to develop a tool for assessing the service availability and readiness of health facilities for providing services as per the NSFs.

Objective 4: to assess the service availability and readiness of public facilities for providing newborn services as per the NSFs.

\section{METHODS}

\section{Study design}

We propose to adopt the Delphi method to identify and finalise the NSFs and relevant indicators through expert consultation and consensus-building. The Delphi technique, mainly developed by Dalkey and Helmer at the Rand Corporation in the 1950 s, which is a widely used and accepted method for achieving convergence of opinion concerning real-world knowledge solicited from experts within specific topic areas. ${ }^{13} 14$ The consensus in the Delphi method is obtained through multiple iterations of ranking surveys and controlled feedback from the expert panel. ${ }^{15}$ The ranking survey may adopt a structured questionnaire and the controlled feedback is done through sharing of the survey results for review, discuss and change of opinion. The Delphi survey attempts to address 'what could/should be' rather than the traditional survey which explores 'what is' ${ }^{16}$ For assessing the newborn service availability and readiness of health facilities in Bangladesh, we will conduct a health facility assessment (HFA) survey. Table 1 describes the summary of the study summary, sample size, data collection and data analysis approaches.

Detail method for each of the objectives are presented below:

\section{Objective 1}

We will adopt a five-step Delphi process for identification of NSFs in Bangladesh.

\section{Step 1-formation of the expert panel}

We propose to form an expert panel consisting of newborn experts in Bangladesh. The National Technical Working Committee, the highest technical body on Newborn Health in Bangladesh (formed by Ministry of Health and Family Welfare, MoHFW) will be requested to form the 
Table 1 Study summary of the process, sample size, data collection and analysis by objective

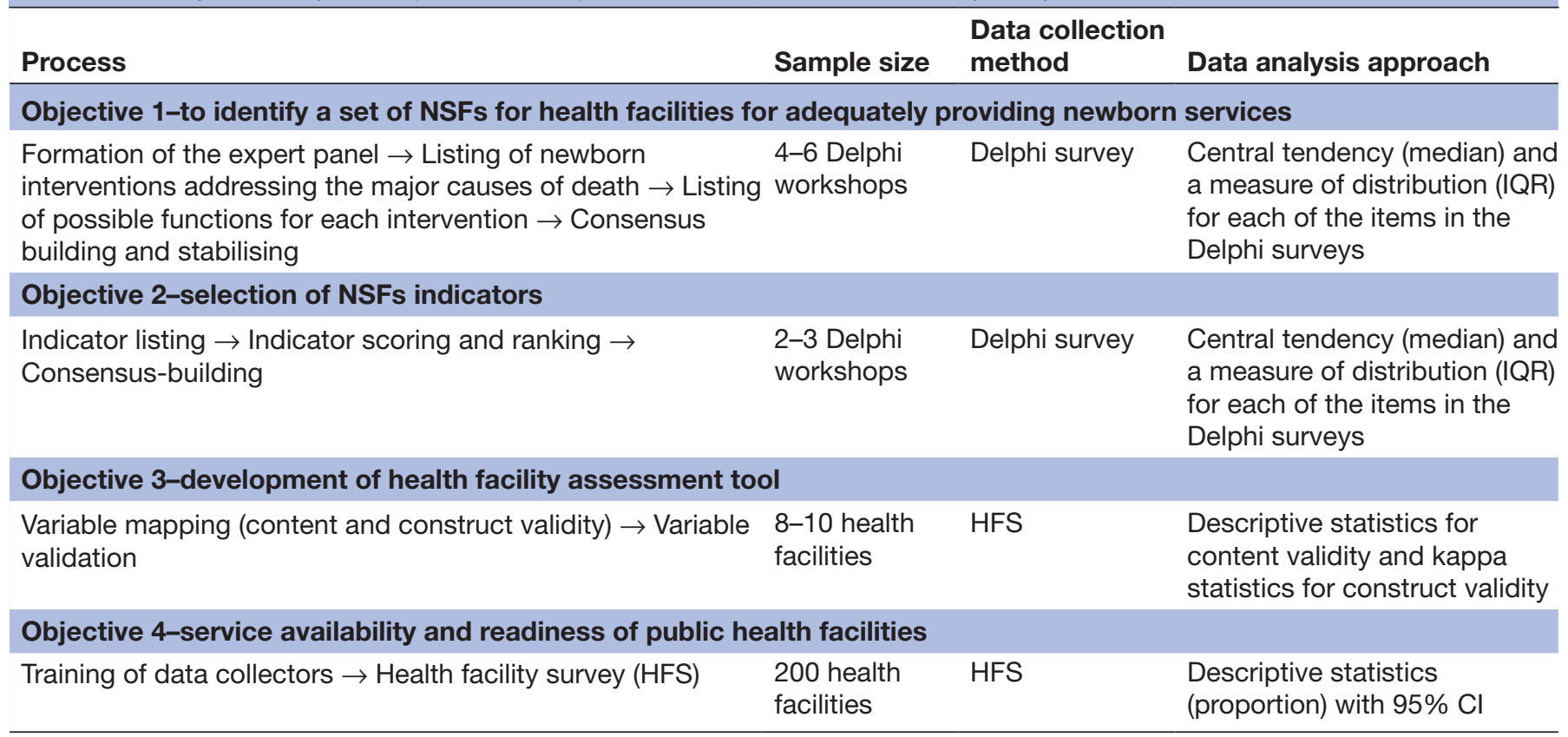

NSF, newborn signal function.

expert panel with specific terms of reference for identifying the NSFs in Bangladesh. Moreover, we will use snowball sampling to identify other potential newborn and health system experts. We will ask the purposive sample of experts to suggest names (and email contact) of other relevant stakeholders. The expert panel will have representatives from the MoHFW, professional bodies, UN agencies, and development partners working in newborn health and measurement experts. The expert panel will be finalised after receiving confirmation from each panellist regarding his/her interest and availability to participate throughout the process. In addition, before each of the Delphi survey workshops, the programme manager of NNHP and IMCI, DGHS, MoHFW will send an official call up letter to each member of the expert panel to participate in the workshop; which will contribute to ensuring maximum participation.

Step 2-listing of newborn interventions addressing the major causes of death

\section{Desk review}

A desk review will be conducted to identify the major causes of newborn death and relevant interventions as per the existing global, regional and national strategies and relevant guidelines.

\section{Key informant interviews}

Following the desk review a series of key informant interview (KIIs) will be conducted with MoHFW programme managers and clinical experts to explore other newborn intervention which is not mentioned in the national and global strategies and guidelines.

\section{Workshop}

A workshop will be organised with the expert panel to finalise the list of newborn interventions. At first, objectives and proposed methodology for identifying NSFs will be presented in the workshop, and necessary modification will be made in the methodology based on expert feedback. Then, the details of Delphi method and specific roles of the expert panel will be described. Finally, the list of newborn interventions identified through desk review and KIIs will be presented before the expert panel (table 2). The list will be updated (if needed) in consultation with the expert panel. The expert panel will be asked to rank the interventions as per the importance and relevance to the Bangladesh context. A four-point Likert scale will be used for the scoring exercise (1=absolutely not essential; $2=$ moderately not essential; $3=$ =moderately essential; $4=$ absolutely essential). Since we want the expert panel to select or reject an intervention as a signal function, we will use an even number Likert scale to avoid neutral positions. Each member of the expert panel will

Table 2 Scoring and ranking of newborn interventions (illustrative)

S.

No Cause of death Intervention Scoring Ranking

\begin{tabular}{lll}
1 & $X$ & A \\
2 & & B \\
3 & & C \\
4 & $Y$ & D \\
5 & & E \\
\hline
\end{tabular}


be asked to assign a score for each of the interventions. Anonymity will be maintained throughout the ranking and scoring process during Delphi survey. The following table outlines the scoring/ranking options and processes. The most important and relevant interventions will be selected based on this ranking and consensus-building exercise.

\section{Step 3-listing of possible functions for each intervention}

\section{Desk review}

A thorough desk review of the available literature (both published and unpublished) will be conducted to identify possible functions (skills and services required to deliver an intervention) for each of the listed interventions. The desk review will also help to identify relevant initiatives (identification of NSFs) and key learnings.

\section{Key informant interviews}

Following the desk review, a series of KIIs will be conducted with MoHFW programme managers and clinical experts to explore other functions required to deliver the newborn interventions which were prioritised in the previous Delphi round.

\section{Workshop}

Workshop will be organised with the expert panel to finalise the list of newborn functions for each of the prioritised interventions. The list of functions identified through the desk review and KIIs will be presented before the expert panel. An open discussion will take place to make necessary modification to the list (inclusion or exclusion).

\section{Step 4-workshop on consensus building Workshop}

A workshop will be organised with the expert panel to score the interventions as per the importance and relevance to the Bangladesh context. A four-point Likert scale will be used for the scoring and ranking the functions as per basic and comprehensive care $(1=$ absolutely not essential; $2=$ moderately not essential; $3=$ moderately essential; 4=absolutely essential) (table 3).

The data collected through this ranking exercise will be analysed for agreement and consensus. Following that, another workshop will be organised with the expert panel in which the results from the previous round of the Delphi survey (scoring) will be presented. Each panellist will be provided with information on average group score and the score previously assigned by him/her for each intervention. Then, the panellists will be asked to rescore the functions independently and anonymously (table 4). The panellists will be asked to explain the reason if he/ she changes his/her previous score (if needed). Data collected through the previous round of Delphi survey (rescoring) will be analysed for agreement, consensus and stability.

\section{Step 5-consensus building and stabilising Workshop}

A workshop will be organised for consensus-building around the prioritised functions. At first, the results from the previous round of the Delphi survey (rescoring) will be shared with the expert panel. The signal functions will be ranked according to their scores. An open discussion will take place regarding the average score and rank of each of the functions. A list of 8-16 signal functions will be identified based on their scores and open discussion. They will be regarded as the final NSFs for Bangladesh. ${ }^{17}$

\section{Objective 2}

After identifying the NSFs, we propose to select 1-2 indicators for assessing the service availability and readiness of health facilities for each signal function. The Delphi process of prioritisation and consensus building will be followed for identification and finalisation of these indicators.

\section{Step 1-indicator listing}

\section{Desk review}

A thorough desk review will be conducted to identify possible indicators for each of the NSFs listed in the previous stage.

\section{Workshop}

A workshop will be organised where the list of identified indicators will be shared with the expert panel and the list will be finalised through open discussion.

Table 3 Scoring and ranking of newborn functions (illustrative)

\begin{tabular}{|c|c|c|c|c|c|c|c|}
\hline \multirow[b]{2}{*}{ S. No } & \multirow[b]{2}{*}{ Cause of death } & \multirow[b]{2}{*}{ Intervention } & \multirow[b]{2}{*}{ Function } & \multicolumn{2}{|c|}{ Basic care } & \multicolumn{2}{|c|}{ Comprehensive care } \\
\hline & & & & Scoring & Ranking & Scoring & Ranking \\
\hline 1 & $x$ & A & A1 & & & & \\
\hline 2 & & A & $\mathrm{A} 2$ & & & & \\
\hline 3 & & B & B1 & & & & \\
\hline 4 & & B & B2 & & & & \\
\hline 5 & Y & $D$ & D1 & & & & \\
\hline 6 & & E & E1 & & & & \\
\hline 7 & & E & E2 & & & & \\
\hline
\end{tabular}


Table 4 Rescoring and reranking of newborn functions as per the interventions

\begin{tabular}{|c|c|c|c|c|c|c|c|c|c|c|c|c|c|c|c|}
\hline \multirow{3}{*}{$\begin{array}{l}\text { S. } \\
\text { No }\end{array}$} & \multirow{3}{*}{$\begin{array}{l}\text { Cause of } \\
\text { death }\end{array}$} & \multirow[b]{3}{*}{ Intervention } & \multirow[b]{3}{*}{ Function } & \multicolumn{4}{|c|}{$\begin{array}{l}\text { The previous round } \\
\text { of score and rank by } \\
\text { individual panellist }\end{array}$} & \multicolumn{4}{|c|}{$\begin{array}{l}\text { The previous round of } \\
\text { average score and rank } \\
\text { by the expert panel }\end{array}$} & \multicolumn{4}{|c|}{$\begin{array}{l}\text { New score and rank by } \\
\text { individual panellist }\end{array}$} \\
\hline & & & & \multicolumn{2}{|c|}{$\begin{array}{l}\text { Basic } \\
\text { care } \\
\end{array}$} & \multicolumn{2}{|c|}{$\begin{array}{l}\text { Comprehensive } \\
\text { care }\end{array}$} & \multicolumn{2}{|c|}{$\begin{array}{l}\text { Basic } \\
\text { care } \\
\end{array}$} & \multicolumn{2}{|c|}{$\begin{array}{l}\text { Comprehensive } \\
\text { care }\end{array}$} & \multicolumn{2}{|c|}{$\begin{array}{l}\text { Basic } \\
\text { care }\end{array}$} & \multicolumn{2}{|c|}{$\begin{array}{l}\text { Comprehensive } \\
\text { care }\end{array}$} \\
\hline & & & & $S$ & $\mathbf{R}$ & $S$ & $\mathbf{R}$ & $S$ & $\overline{\mathbf{R}}$ & $S$ & $\mathbf{R}$ & $S$ & $\mathbf{R}$ & $\mathrm{s}$ & $\mathbf{R}$ \\
\hline 1 & $X$ & $A$ & $\mathrm{~A} 1$ & & & & & & & & & & & & \\
\hline 3 & & B & B1 & & & & & & & & & & & & \\
\hline 4 & & B & B2 & & & & & & & & & & & & \\
\hline 5 & $\mathrm{Y}$ & $\mathrm{D}$ & D1 & & & & & & & & & & & & \\
\hline 6 & & $E$ & $\mathrm{E} 1$ & & & & & & & & & & & & \\
\hline
\end{tabular}

$\mathrm{R}$, rank; S, score.

Table 5 Scoring and ranking of newborn signal functions (NSFs) indicators

\begin{tabular}{|c|c|c|c|c|c|c|}
\hline \multirow[t]{2}{*}{$\begin{array}{l}\text { S. } \\
\text { No }\end{array}$} & \multirow[t]{2}{*}{ NSFs } & \multirow[b]{2}{*}{ Indicator } & \multicolumn{2}{|c|}{ Importance } & \multicolumn{2}{|c|}{$\begin{array}{l}\text { Feasibility of data } \\
\text { collection }\end{array}$} \\
\hline & & & Score & Rank & Score & Rank \\
\hline 1 & $x$ & A & & & & \\
\hline 2 & $x$ & B & & & & \\
\hline 3 & $x$ & $\mathrm{C}$ & & & & \\
\hline 4 & $Y$ & $\mathrm{D}$ & & & & \\
\hline 5 & $Y$ & $E$ & & & & \\
\hline
\end{tabular}

Importance: 1=absolutely not essential; $2=$ moderately not essential; $3=$ moderately essential; $4=$ absolutely essential. Feasibility: $1=$ absolutely not feasible; $2=$ moderately not feasible; $3=$ moderately feasible; $4=$ absolutely feasible.

\section{Step 2-indicator scoring and ranking}

The indicators identified through desk review and consultative workshops will be ranked through a Delphi survey (table 5). One to two indicators will be selected for each signal function through this exercise. At first, the expert panel will be asked to score the indicators. The NSF indicators identified through the previous round of discussion will be prioritised through a Delphi survey. The indicators will be scored according to their importance and feasibility of data collection. The following table outlines the scoring/ranking options and processes.

The data collected through this scoring exercise will be analysed for agreement and consensus. Following that, another workshop will be organised with the expert panel where the results from the previous round of Delphi survey (scoring) will be presented. Each panellist will be provided with information on average group score and the score previously assigned by him/her for each indicator. Then, the panellists will be asked to rescore the indicators independently and anonymously and to explain the reason if he/she changes his/her previous score (if needed) (table 6).

Data collected through previous rounds of Delphi survey (rescoring) will be analysed for agreement, consensus and stability.

\section{Step 3-consensus-building}

Following that, another workshop will be organised for consensus-building around the prioritised indicators. At first, the results from the previous round of Delphi survey (rescoring) will be shared with the expert panel. The proposed signal function indicators will be ranked according to their scores. An open discussion will take place regarding the average score and rank of each of the indicator. One to two indicators will be selected based on their scores and open discussion. They will be regarded as the final NSF indicators for Bangladesh.

\section{Objective 3}

Step 1-variable mapping

Once the NSF indicators are finalised, we will identify variables (numerators and denominators) required for measuring these indicators. Then, we will conduct a desk review to map the variables in existing HFA tools. We will consider the Bangladesh Health Facility Survey (BHFS) 2014 tool as our base document for this mapping exercise.

Variables that are already present in the BHFS tool 2017 will be automatically included in the list. For variables, that are not included in the BHFS 2017, we will categorise them in two types:

- Type 1: variables that are absent in the BHFS 2017 tool but present in other validated HFA tools.

- Type 2: variables that are absent in both the BHFS 2017 tool and other validated tools.

For type 1 variables, we will directly incorporate them into the BHFS 2017 tool. However, for type 2 variables, we will incorporate them in the BHFS 2017 tool after validation. 


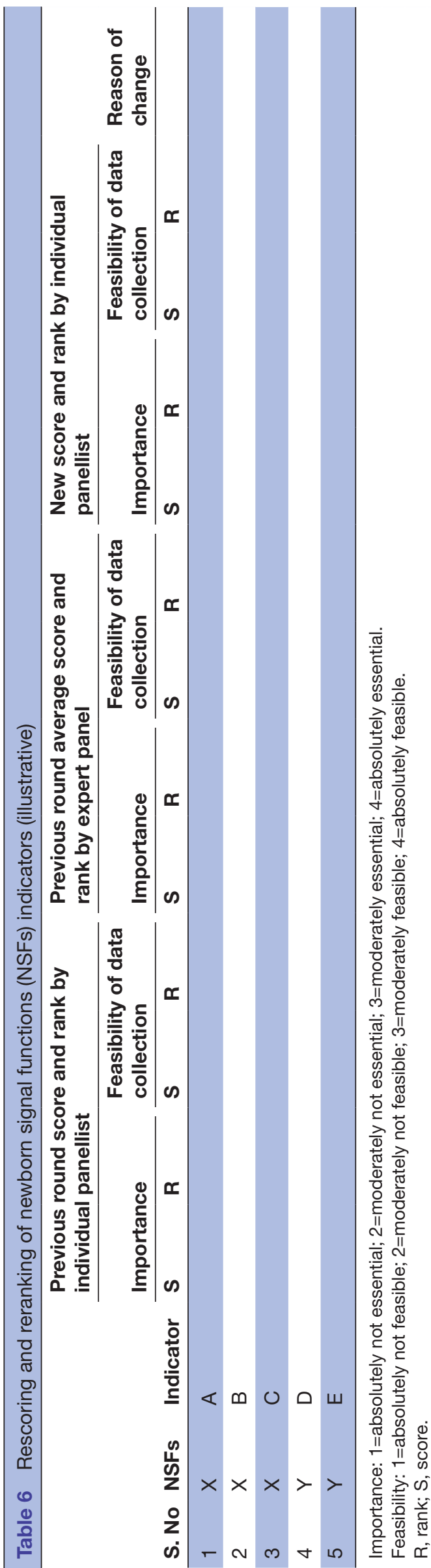

Step 2-variable validation

We will assess the content validity of type-2 variables through consultation with the expert panel. Construct validity will be measured through field testing. The field testing will be conducted by project research physicians (PRPs). In addition, in-depth interviews will be conducted with the facility managers and health service providers to explore the opinions of respondents regarding the type-2 variables. Finally, the BHFS 2017 tool will be updated with all type 1 and type 2 variables.

\section{Objective 4}

We propose to conduct an HFA survey to assess the service availability and readiness of public health facilities as per the NSFs. The updated HFA tool (developed through this exercise) will be used for this purpose.

\section{Sample size by objective}

Objectives 1 and 2

Six to nine Delphi survey workshops will be organised to identify a set of NSFs and NSF indicators. We are also expecting to conduct 4-6 KIIs for this purpose.

Objective 3

Tool pretesting will be conducted in $8-10$ health facilities to finalise the HFA tool.

Objective 4

A precision-based sample size was calculated to assess the service availability and readiness of public hospitals and health facilities as per the NSFs. Since there is no existing estimate, we aim to cover maximum variance $(50 \%)$ with $10 \%$ error margin. Assuming a non-response rate of around $5 \%,{ }^{18}$ the required sample size is 101 public facilities.

There are 64 districts in Bangladesh. Each district has 6-12 subdistricts (upazila) and each subdistrict has 8-10 unions. In each district there is a District Hospital (DH) (tertiary level referral facility) and a Maternal and Child Welfare Centre (MCWC) (primary level referral facility dedicated for maternal and child health). In each Upazila (subdistrict), there is an Upazila Health Complexes (UHC) (primary level referral facility). In each union, there is one Union Health and Family Welfare Centers (UHFWC) (primary health centre) and 3-4 community clinics (CCs) (primary health outpost centre).

We will randomly select 21 districts. The DHs and the MCWCs of the selected district will be surveyed. We will then randomly select one subdistrict from the selected district and the UHC of the selected subdistrict will be surveyed. We will randomly select one union from each subdistrict and the UHFWC of the selected union will be surveyed. We will also randomly select one CC from each of the selected unions for survey.

Data collection by objective

Objectives 1 and 2

Data will be collected through organising a workshop with expert panel members. The panel members will be 
asked to score and rank each intervention in a structured tool. Once the intervention list is finalised, another workshop will be organised for scoring and ranking of the functions that are required to provide the selected interventions. The same process will be followed to collect data on scoring and ranking of each of the indicators. A social scientist/qualitative researcher will conduct KII with MoHFW programme managers and clinical experts to explore the newborn interventions and functions that are required to provide these interventions.

\section{Objective 3}

The field testing of new HFA tool will be conducted by PRPs in $8-10$ health facilities to understand validity. A social scientist/qualitative researcher will conduct in-depth interviews with the hospital managers and health service providers to explore the opinions of prospective respondents regarding the type-2 variables.

\section{Objective 4}

The HFA surveys will be conducted to assess the service availability and readiness of the participating facilities as per the NSFs. The assessment team will consist of two PRPs who will be specially trained in HFA for NSFs. The assessment team will assess the health facility using the HFA tool for NSFs.

\section{Data quality monitoring}

Regarding the identification of NSFs, we have to rely on the scoring and ranking exercise of the expert panel. Regarding HFA survey, periodic and sudden spot checks will be conducted by the central level experts to assess the completeness and validity of documentation. The study team will facilitate the supervision process.

\section{Data management}

The database will be managed in structured query language (SQL) server 2008. The server will be password protected and only the developer will have permission to $\log$ in to the database. All possible data validations system like consistency check, logical check, range check, uniqueness check, skip rules, and so on will be in-built to prevent errors or inconsistency in data entry.

\section{Data analysis by objective}

\section{Quantitative: objectives 1 and 2}

Central tendency (median) and a measure of dispersion (IQR) will be presented for each of the items in the Delphi surveys. Study shows that convergence of ideas and reasoning towards a subjective central tendency measure has to be there to achieve consensus. ${ }^{19}{ }^{20}$ Agreement and consensus will be considered to be achieved (for including in the final list) if the median value an item is 3 or more and IQR is $\leq 1 .{ }^{1921}$ The rule of thumb is that for a five-point or four-point Likert scale, an IQR of one or less is a suitable indication of consensus. For a four-point Likert scale, an IQR of one or less than 1 means that more than $75 \%$ of all opinions fall within 1 point on the scale. Stability of response measures the reliability of results and refers to the level of agreement between rounds. In order to measure stability, we will include all items in subsequent rounds (even if they have achieved consensus in the previous round). Since the data are ordinal (Likert scale), we will use the Wilcoxon matched-pair signedrank test to measure the stability of individual scoring (by a panellist) between rounds. Consensus and agreement will be considered stable when there is no significant change between rounds.

\section{Objective 3}

Content validity of the newly added variables will be checked with descriptive statistics (proportions). Content validity will be considered to be achieved when more than $80 \%$ of the participant agrees that the language of the newly added question appropriately reflects the content/variable that it is supposed to measure. Kappa statistics will be used to report on the construct validity of the newly added variables (PRPs vs healthcare provider). Construct validity of the variable will be considered to be achieved if the kappa statistics is $\geq 0.75$.

\section{Objective 4}

Descriptive statistics (proportion) with a 95\% CI will be used to report the level of service availability and readiness of public facilities regarding NSFs. The estimates will be disaggregated based on the type of facilities.

\section{Desk review and qualitative analysis}

All KIIs will be audio-recorded and then transcribed. The interviews will be conducted in Bangla. First, the researchers will read all transcripts to achieve data familiarisation. Then the transcripts will be reviewed by the investigators and a primary code book will be developed based on which coding categories will be constructed by the investigators. We will adopt a content analysis approach for desk review and qualitative analysis.

\section{Patient and public involvement}

The Delphi experts will be involved throughout the study providing their feedbacks and opinions during Delphi workshops and Delphi surveys. Their feedbacks will be incorporated to finalise the Delphi survey tool, to identify and rank NSFs, and HFA tool. The HFA tool will be used by local-level health managers and supervisors. Delphi experts will also be invited to participate in dissemination events and to develop dissemination materials. This study will assess public health facilities and thus will use only facility data without patient recruitment. We will disseminate the results through dissemination workshops, research briefs, posters, report writing and scientific writing to newborn experts, researchers, public health professionals, policy makers and others who represents government, non-government (NGO) and development organisations.

Throughout this study, patient involvement is not required. Patients were not invited to comment on the study design or will not be consulted to interpret the results. 


\section{DISCUSSION}

Service availability and readiness of health facilities can play a determining role in the ability of health systems to cater to health services to the target population. Inadequate service availability and readiness of health facilities for providing healthy and sick newborn care may act as a significant barrier to achieving effective coverage of these interventions at scale. ${ }^{22-27}$ Therefore, strategic focus and significant investments are required to increase service provision, availability, readiness and quality of care pertaining to the priority newborn interventions in different levels of health facilities in Bangladesh. In addition, the readiness and performance of health facilities in delivering these interventions needs to be closely monitored and tracked. However, monitoring service availability and readiness of health facilities is often a weak component of health systems in resource poor settings. ${ }^{28}$ The result of this study will contribute to assessing the service availability and readiness of a health facility for delivering specific interventions. In addition, it will help in categorising health facilities and will assist policy makers and health managers to appropriately plan and adequately monitor the progress and performance of health facilities. ${ }^{29}$

There have been some attempts to develop signal functions for paediatric care, but there has not been a consensus. A Delphi study was conducted to identify a set of quality of care indicators for paediatric inpatient care in Kenya. ${ }^{30}$ The study selected six common paediatric conditions and identified relevant indicators after assessing their perceived validity and acceptability through expert consultation. Most of the indicators were rated considering outcome, reliability, actionability and priority. However, less attention was given in considering the feasibility of data collection during rating. Similarly, the Pakistan Initiative for Maternal and Newborns study conducted an HFA survey in 2005 and used some criteria for categorising facilities to basic and comprehensive care. ${ }^{31}$ However, none of these attempts could identify a comprehensive list of signal functions for newborn services. ${ }^{30} 31$ Our study will score and rank the indicators considering importance (impact, reliability, actionability, priority) and feasibility of data collection.

Another attempt was undertaken in Zimbabwe to identify a set of signal functions for emergency newborn care. ${ }^{32} \mathrm{Six}$ basic and three comprehensive emergency newborn care signal functions were identified by the Zimbabwe Reproductive Health Steering Committee. However, there was no transparent guideline on coverage standards and content for emergency newborn care. Moreover, categories were not consistent as there was non-emergency routine care included, namely, thermal care. There were some other relevant initiatives to address this issue, but none of these was able to develop a comprehensive list of NSFs. ${ }^{11} 30$ 32-35 The London School of Hygiene and Tropical Medicine has also undertaken an initiative to identify a set of signal functions through a global consultative process. Our study will identify a comprehensive list of NSFs through a structured process of scoring, ranking, rescoring, reranking, consensus building and stabilisation.
The BHFS is a nationally representative health facility survey designed to assess the readiness of public, NGO and private healthcare facilities in Bangladesh. The BHFS reports newborn resuscitation as the only NSFs that is approved by $\mathrm{WHO}$ as a recommended EmONC signal functions. This is not enough to adequately assess service availability and readiness of a health facility to cater to newborn services. A set of NSFs is the prerequisite to assessing the readiness of a health facility for delivering newborn interventions. Our study will identify a set of NSFs Indicators along with identifying variables required for measuring those indicators. Afterwards, the selected variables will be validated. The HFA tool is updated as per the validated variables which will be able to comprehensively assess the service availability and readiness of health facilities regarding newborn services.

To date, there are no globally or nationally recognised signal functions through which the service availability and readiness of a health facility to deliver newborn services can be assessed. We anticipate that this study will be able to develop a widely agreed-upon set of NSFs that will assist in updating the HFA tool of Bangladesh. The result of the study will inform us regarding the actual readiness of health facilities in providing newborn healthcare services. The result will also contribute to categorising health facilities as basic and comprehensive newborn care facilities. The study findings will assist policymakers and health managers to appropriately plan and adequately monitor the progress and performance of health facilities delivering newborn healthcare in Bangladesh.

\section{Ethics and consent to participate}

Ethical approval to conduct the study is obtained from the Institutional Review Board of icddr, b (PR-17089). Written and informed consent will be obtained from all the participants. Privacy and confidentially of respondents will strictly be maintained. Confidentiality of data will be assured at all steps of data collection, data management, and analysis. All personal identifiers (ie, name and addresses) will be removed before analysis. In addition, the data (Delphi Survey, KII and HFS) will be kept underlock and key for protecting privacy.

\section{Dissemination plan}

The planned completion date of the present study is 31 September 2020. We will publish our findings in a peerreviewed journal and may also present them at conferences and workshops. We will also develop detailed report.

\section{Author affiliations}

${ }^{1}$ Maternal and Child Health Division, International Centre for Diarrhoeal Disease Research, Dhaka, Bangladesh

${ }^{2}$ Directorate General of Health Services, Government of Bangladesh Ministry of Health and Family Welfare, Dhaka, Bangladesh

${ }^{3}$ Director General of Family planning, Government of Bangladesh Ministry of Health and Family Welfare, Dhaka, Bangladesh

${ }^{4}$ Neonatology, BSMMU, Dhaka, Bangladesh

${ }^{5}$ UNICEF Bangladesh, Dhaka, Bangladesh

${ }^{6}$ USAID Bangladesh, Dhaka, Bangladesh

${ }^{7}$ WHO Bangladesh, Dhaka, Bangladesh

${ }^{8}$ RTM International, Dhaka, Bangladesh 
${ }^{9}$ NIPORT, Dhaka, Bangladesh

${ }^{10}$ Ipas, Dhaka, Bangladesh

${ }^{11}$ Save the Children Bangladesh, Dhaka, Bangladesh

Twitter Sanjoy Kumer Dey @Sanjoy Kumer Dey

Acknowledgements The authors would like to acknowledge the contribution of the Government of Bangladesh to this project. We also would like to give a special thanks to all the technical committee members from DGHS, DGFP, Bangladesh Paediatric Association (BPA), Bangladesh Neonatal Forum (BNF), WHO, UNICEF, Save the Children, USAID, National Institute of Population Research and Training (NIPORT) without whose dedication and expertise this protocol could not be developed.

Collaborators NSF-BD study group: Soofia Khatoon, Tahmina Begum, Zakia Nahar, Begum Sharifun Nahar, Dilara Alo, Mahbubul Haque, Sultan Md Shamsuzzaman, Md Moklesur Rahman, Khaleda Islam, Altaf Hossain, Tanveer Ahmed Chowdhury, Md Emdadul Haque, Sabina Ashrafee Lipi, Md Abdul Wadud, Mahfuza Akhter, Md Abdul Majid, Nasima Khatun, Prodip Kumar Saha, Noor Riffat Ara, Md Faizur Rahman, Supriya Sarker, Ahsanul Alam, Sabbir Ahmed, Md Rezaul Hasan, Suman Kanti Chowdhury, Monisha Banarjee, Ehtesham Kabir

Contributors AER is the principal investigator and GB is the coinvestigator of the study jointly developed the first draft of the manuscript as a first author. AER and GB contributed significantly in designing the study, development of data collection instruments and preparation of the first draft of the manuscript. SM, TT, JI, FU, MUII, MdAM, SKD, SSultana, FM, MK, AA, AAIS, SSharmin, ZA, SR, JG, AK, MS and SEA were involved with development of the protocol and reviewed the manuscript. SEA lead the process as a senior author.

Funding The study was supported by the United States Agency for International Development (USAID) under the terms of USAID's Research for Decision Makers (RDM) Activity cooperative agreement no. AID-388-A-17-00006 and grant no.-01546.

Competing interests None declared.

Patient and public involvement Patients and/or the public were not involved in the design, or conduct, or reporting, or dissemination plans of this research.

Patient consent for publication Not required.

Provenance and peer review Not commissioned; externally peer reviewed.

Open access This is an open access article distributed in accordance with the Creative Commons Attribution Non Commercial (CC BY-NC 4.0) license, which permits others to distribute, remix, adapt, build upon this work non-commercially, and license their derivative works on different terms, provided the original work is properly cited, appropriate credit is given, any changes made indicated, and the use is non-commercial. See: http://creativecommons.org/licenses/by-nc/4.0/.

\section{ORCID iDs}

Ahmed Ehsanur Rahman http://orcid.org/0000-0001-9216-1079

Shema Mhajabin http://orcid.org/0000-0001-7023-015X

\section{REFERENCES}

1 UNICEF, World Health Organization, The World Bank, United Nations Population Division. Levels \& trends in child mortality: report 2015estimates developed by the UN inter-agency group for child mortality estimation, 2015

2 United Nations. Sustainable development goals, 2016. Available: http://www.un.org/sustainabledevelopment/

3 Requejo JH, Bryce J, Barros AJD, et al. Countdown to 2015 and beyond: fulfilling the health agenda for women and children. Lancet 2015;385:466-76.

4 Victora CG, Requejo JH, Barros AJD, et al. Countdown to 2015: a decade of tracking progress for maternal, newborn, and child survival. Lancet 2016;387:2049-59.

5 National Institute of Population Research and Training (NIPORT), Mitra and Associates, ICF International. Bangladesh demographic and health survey 2014. Dhaka, Bangladesh and Calverton, Maryland, USA, 2016

6 Ministry of Health and Family Welfare GotPsRoB. Committing to child survival: a promise renewed declaration 2013. Dhaka, Bangladesh, 2013.

7 Lawn JE, Blencowe H, Oza S, et al. Every newborn: progress, priorities, and potential beyond survival. Lancet 2014;384:189-205.
8 Kinney MV, Cocoman O, Dickson KE, et al. Implementation of the every newborn action plan: progress and lessons learned. Semin Perinatol 2015;39:326-37.

9 World Health Organization. Essential elements of obstetric care at first referral level. Geneva, 1991.

10 WHO U, UNICEF. Guidelines for the monitoring and use of obstetric services. New York: UNICEF, 1997.

11 Gabrysch S, Civitelli G, Edmond KM, et al. New signal functions to measure the ability of health facilities to provide routine and emergency newborn care. PLoS Med 2012;9:e1001340.

12 DeRenzi B, Parikh T, Mitchell M, et al. e-IMCl: improving pediatric health care in low-income countries. chi 2008: 26th annual chi conference on human factors in computing systems Vols 1 and 2 , conference proceedings 2008:753-62.

13 Dalkey NC. Studies in the quality of life delphi and decision-making. Lexington Books, 1972.

14 Hsu C-C, Sandford BA. The delphi technique: making sense of consensus. Prac Assess Res Eval 2007:12:1-8.

15 Ludwig B. Predicting the future: have you considered using the delphi methodology? J Extension 1997;35.

16 Miller $\mathrm{G}$. The development of indicators for sustainable tourism: results of a delphi survey of tourism researchers. Tour Manag 2001:22:351-62.

17 Trevelyan EG, Robinson PN. Delphi methodology in health research: how to do it? Eur J Integr Med 2015;7:423-8.

18 National Institute of Population Research and Training (NIPORT), ICF International. Bangladesh health facility survey 2017. Dhaka, Bangladesh, 2019.

19 Rayens MK, Hahn EJ. Building consensus using the policy delphi method. Policy Polit Nurs Pract 2000;1:308-15.

20 Holey EA, Feeley JL, Dixon J, et al. An exploration of the use of simple statistics to measure consensus and stability in Delphi studies. BMC Med Res Methodol 2007;7:52.

21 Heiko A. Consensus measurement in delphi studies: review and implications for future quality assurance. Technol Forecast Soc Change 2012;79:1525-36.

22 Hoque DME, Rahman M, Billah SM, et al. An assessment of the quality of care for children in eighteen randomly selected district and sub-district hospitals in Bangladesh. BMC Pediatr 2012;12:197.

23 Rahman AE, lqbal A, Hoque DME, et al. Managing neonatal and early childhood syndromic sepsis in sub-district hospitals in resource poor settings: improvement in quality of care through introduction of a package of interventions in rural Bangladesh. PLoS One 2017;12:e0170267.

24 Moxon SG, Lawn JE, Dickson KE, et al. Inpatient care of small and sick newborns: a multi-country analysis of health system bottlenecks and potential solutions. BMC Pregnancy Childbirth 2015;15:S7.

25 Vesel L, Bergh A-M, Kerber KJ, et al. Kangaroo mother care: a multi-country analysis of health system bottlenecks and potential solutions. BMC Pregnancy Childbirth 2015;15:S5.

26 Wall SN, Lee ACC, Niermeyer S, et al. Neonatal resuscitation in lowresource settings: what, who, and how to overcome challenges to scale up? Int J Gynaecol Obstet 2009;107:S47-64.

27 Kagema F, Ricca J, Rawlins B, et al. Quality of care for prevention and management of common maternal and newborn complications: findings from a national health facility survey in Kenya-are services provided according to international standards. Baltimore: Jhpiego, 2011.

28 Grove J, Claeson M, Bryce J, et al. Maternal, newborn, and child health and the sustainable development goals-a call for sustained and improved measurement. Lancet 2015;386:1511-4.

29 Moran AC, Kerber K, Sitrin D, et al. Measuring coverage in $\mathrm{MNCH}$ : indicators for global tracking of newborn care. PLoS Med 2013;10:e1001415

30 Ntoburi S, Hutchings A, Sanderson C, et al. Development of paediatric quality of inpatient care indicators for low-income countries-a delphi study. BMC Pediatr 2010;10:90.

31 United States Agency for International Development (USAID). The Pakistan initiative for mothers and newborns (PIAMEN), 2005.

32 Ministry of Health \& Child Welfare Zimbabwe. The Zimbabwe national maternal and neonatal health roadmap 2007-2015. Harare: Ministry of Health \& Child Welfare Zimbabwe, 2007.

33 Republic of the Philippines - Department of Health Administrative order number 2008-0029. Implementing health reforms for rapid reduction of maternal and neonatal mortality, 2008.

34 Ministry of Health and Sanitation Sierra Leone. Nationwide needs assessment for emergency obstetric and newborn care services in Sierra Leone. Freetown: Ministry of Health and Sanitation Sierra Leone, 2008

35 Norway-Pakistan Partnership Initiative (NPPI). Feasibility study on result-basedfinancial mechanisms for MNCH, 2009. 